edge is less sharply defined then the outside - or 1 should rather say has its outline less visible for want of contrast, I do not see any difference of depth of shade. Power 565. Enceladus just south of the bright part of ring $B$. The inter. nal edge of the shading of ring $A$, is about one third of its breadth from the division: the inner edge of $A$ is decidedly brighter than the outer, though the outer is brighter than the middle.

Jan. 25. At $5^{\text {h }} 58^{\mathrm{m}}$ G. M.T. The preceding end of dark ring blue and the following lrown, indeed the $N . E$. portion seems browner than the $S$. E. portion. The shadow of the ball upon the ring remarkably angular. It really appears to me that the exterior boundary of the shadow projected on ring $B$ is slightly concave. The shadow of the ring upon the ball has I think become darker, but still is not black. The belt which used to mark the boundary of the blue region of the hall has become very faint if indeed at all visible. The knob on the shadow of the ball $I$ think I never saw so decisively. The projection of the shadow of the ball upon the obscure ring, being, as I have repeatedly observed it, a con. tinuation of the same line or curve as the part projected on $B$ does not support the hypothese's which has been suggested that the obscure ring is not in the same plane as the others. The curvature of the shadow seems to prove a convexity of ring $B$ and probably of $C$ and may explain the diminution of the proportionate breadth of $B$ where it crosses the ba!l which I have repeatedly observed. Its inner edge being dusky and rounded and moreover greatly foreshortened, would become so nearly the colour of $C$ as not to be easily distinguished from it producing the effect of an apparent increase of the breadth of $C$ and correspondent decrease of the breadth of $B$.

Jan. 28. Went up to the observatory to observe Saturn by daylight and had him fixed in the telescope with clockmotion going at $4^{\mathrm{h}} 0^{\mathrm{m}}$ G. M. T. The sun three or four diameters above the horizon. With 565 he appeared pale and no satellites visible nor any trace of the dark ring. The contrast of brightness between rings $A$ and $B$ is by this light far more striking than when the sky is dark. At $4^{\text {h }} 20^{\text {m }}$ I begin to see ring $C$ which is uniform in shade and $I$ see the whole breadth at once. At my first certain glimpse of it, it appeared to reach ahout hall way to the ball. I tried to satisfy myself of a dipision and also of a difference of brightness between the internal and external edges but 1 could not succeed. I f a ncied sometimes the obscure ring broader at the following than the preceding arm. The preceding seems browuish and the following grey or rather the brown tinge is strongest on the south preceding portion. I have watched the development of the dark ring most attentively and I have been nevertheless quite unable to find any division or difference of shade, or that one part appears before another. The sky is rather below the average in quality.

At $6^{\mathrm{h}} 0^{\mathrm{m}} \mathrm{I}$ observed the brown part of the obscure ring seemed to be travelling round, the southern portion of the following arm of $C$ being slightly brown.

Felır. 1j. The development of the obscure ring was again observed in the twilight and certainly it appeared to me to cone out in its full breadth at once. The concavity of the exterior edge of the projection of the shadow of the ball upon the ring appears increasingly evident, perbaps in some degree from the very fine state of the air to night. Its projection also upon $C$ in one unbroken line, renders the curvature more olvious. Yet I acknowledge nyself quite unable to imagine any probable form of the surface of the ring, which would account for the shape of this shadow.

I regret that the state of the weather for the last few weeks (of mid-winter) has not allowed me to pursue my ob. servations upon the changes of colour of the dark ring, which I had hoped might aftord cvidence of its rotation.

Valletta 1853, Febr. 25.

\section{W. Lassell.}

Fernere Beobachtumgen des von Herrn Ferguson entdeckten Planeten, von Hern Director Rümker.

\begin{tabular}{|c|c|c|c|c|}
\hline & M. Zt. Haml. & $\mathbf{A R}$. & Decl. & Vergl. \\
\hline 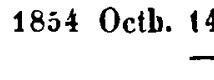 & $\begin{array}{l}8^{\mathrm{h}} 14^{\mathrm{m}} 58^{\mathrm{s}} \\
94555\end{array}$ & 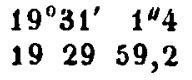 & $\begin{array}{l}-2^{0} 9^{\prime} 47^{u} 1 \\
-2939,4\end{array}$ & $\begin{array}{l}2 \\
7\end{array}$ \\
\hline
\end{tabular}

Scheinharer Ort des Vergleichsterns : $\alpha .=1^{\mathrm{b}} 13^{\mathrm{m}} 29^{\circ} 324 \quad$ o. $=-2^{\circ} 4^{\prime} 22^{\prime \prime} 31$. 